Cite this: Phys. Chem. Chem. Phys., 2013, 15, 3577

Received 30th October 2012, Accepted 22nd January 2013

DOI: $10.1039 / \mathrm{c} 3 \mathrm{cp} 43826 \mathrm{k}$

www.rsc.org/pccp

\title{
Electron-driven ionization of large methanol clusters in helium nanodroplets
}

\author{
Marcelo Goulart, ${ }^{\text {abc }}$ Peter Bartl, ${ }^{a}$ Andreas Mauracher, ${ }^{a}$ Fabio Zappa, ${ }^{c}$ \\ Andrew M. Ellis*d and Paul Scheier*a
}

\begin{abstract}
The electron-driven ionization of helium droplets doped with pure methanol and ethanol clusters has been investigated for the first time using high resolution mass spectrometry. Large clusters are readily accessible by this route, with up to 100 alcohol molecules seen in the present study. The mass spectra for the doped helium droplets show many similarities with previous gas phase mass spectrometric studies of methanol and ethanol clusters. Thus the dominant ion products, at least for small clusters, are the protonated species $\mathrm{H}^{+}\left(\mathrm{CH}_{3} \mathrm{OH}\right)_{n}$ and $\mathrm{H}^{+}\left(\mathrm{C}_{2} \mathrm{H}_{5} \mathrm{OH}\right)_{n}$. Likewise intra-cluster reaction is observed to produce $\mathrm{H}^{+}\left(\mathrm{H}_{2} \mathrm{O}\right)\left(\mathrm{CH}_{3} \mathrm{OH}\right)_{n}$ and $\mathrm{H}^{+}\left(\mathrm{H}_{2} \mathrm{O}\right)\left(\mathrm{C}_{2} \mathrm{H}_{5} \mathrm{OH}\right)_{n}$ ions. However, in helium droplets the observation of consecutive intra-cluster reactions is seen with product molecules containing up to five water molecules. The evidence points towards the proton locating on $\mathrm{H}_{2} \mathrm{O}$ to form $\mathrm{H}_{3} \mathrm{O}^{+}$, rather than the alcohol, despite the higher proton affinity of the latter. The behaviour of the $\mathrm{H}^{+}\left(\mathrm{H}_{2} \mathrm{O}\right)_{m}(\mathrm{ROH})_{n}$ ion signals as a function of cluster size is consistent with the most stable cluster structures arising from a central $\mathrm{H}_{3} \mathrm{O}^{+}$ion surrounded by two or more complete five-membered rings with the constituents held in place by hydrogen bonds.
\end{abstract}

\section{Introduction}

Proton solvation is of central importance in solution chemistry. In aqueous solutions protons have high mobilities which are explained by the Grotthus mechanism, ${ }^{1}$ whereby the proton is transported along a network of hydrogen bonded water molecules via the facile interchange of two different ion cores, the Eigen $\left(\mathrm{H}_{9} \mathrm{O}_{4}{ }^{+}\right)$and Zundel $\left(\mathrm{H}_{5} \mathrm{O}_{2}{ }^{+}\right)$cations. ${ }^{2,3}$ The critical role implied here for $\mathrm{H}^{+}\left(\mathrm{H}_{2} \mathrm{O}\right)_{n}$ clusters has made the Zundel and Eigen ions, along with their more solvated analogues, the target of numerous experimental and theoretical studies (for reviews see ref. 4-7).

Methanol is another protic solvent that exhibits a high proton mobility. The mechanistic details of this mobility are not as well understood as for water, but recent studies of small, protonated, methanol clusters using infrared spectroscopy suggest intermolecular proton transfer could be an important proton migration mechanism. ${ }^{8}$ This proton transfer process

\footnotetext{
${ }^{a}$ Institut für Ionenphysik und Angewandte Physik, Universität Innsbruck, Technikerstr. 25, A-6020 Innsbruck, Austria. E-mail: Paul.Scheier@uibk.ac.at

${ }^{b}$ CAPES Foundation, Ministry of Education of Brazil, Brasília - DF 70040-020, Brazil

${ }^{c}$ Departamento de Física, ICE, UFJF, Campus Universitário, Juiz de Fora, MG - 36036-330, Brazil

${ }^{d}$ Department of Chemistry, University of Leicester, University Road,

Leicester LE1 7RH, UK. E-mail: Andrew.Ellis@le.ac.uk
}

appears to be assisted by a sequence of simple structural changes with relatively small activation barriers. Of course there are important differences between protonated water cluster ions and protonated methanol cluster ions, most notably the presence of a methyl group, which will inevitably impact upon the proton transfer reaction mechanism through its alteration of the network of hydrogen bonds.

One of the challenges in cluster science is to explore how structure and chemistry change with cluster size, and thereby draw parallels with behaviour in bulk solutions. The study of protonated methanol cluster ions has a history dating back many years. It was established early on that the dominant products obtained from ionization of small methanol clusters, whether by electron impact or photoionization, are the protonated cluster ions, $\mathrm{H}^{+}\left(\mathrm{CH}_{3} \mathrm{OH}\right)_{n}{ }^{9-11}$ Similar to water clusters, major structural changes between the neutral methanol clusters and the corresponding cations deliver excess energy into the latter which leads to rapid ejection of an $\mathrm{OCH}_{3}$ entity, i.e.

$$
\left(\mathrm{CH}_{3} \mathrm{OH}\right)_{n} \rightarrow \mathrm{H}^{+}\left(\mathrm{CH}_{3} \mathrm{OH}\right)_{n-1}+\mathrm{OCH}_{3}+\mathrm{e}^{-}
$$

Some interesting size-dependent intra-cluster chemistry has been found for protonated methanol clusters using mass spectrometry. For the protonated dimer, $\mathrm{H}^{+}\left(\mathrm{CH}_{3} \mathrm{OH}\right)_{2}$, produced by multiphoton ionization of neutral methanol clusters, 
Morgan and Castleman observed that this ion underwent a delayed reaction leading to protonated dimethyl ether (DME) and ejection of neutral $\mathrm{H}_{2} \mathrm{O} .{ }^{12}$ No such reaction was found for larger cluster ions but in a subsequent study, again using multiphoton ionization, Morgan and co-workers observed elimination of neutral DME (along with methanol) but retention of $\mathrm{H}_{2} \mathrm{O}$ for $n \geq 7,{ }^{13}$ i.e.

$\mathrm{H}^{+}\left(\mathrm{CH}_{3} \mathrm{OH}\right)_{n} \rightarrow \mathrm{H}^{+}\left(\mathrm{H}_{2} \mathrm{O}\right)\left(\mathrm{CH}_{3} \mathrm{OH}\right)_{n-3}+\mathrm{CH}_{3} \mathrm{OH}+\mathrm{CH}_{3} \mathrm{OCH}_{3}+\mathrm{e}^{-}$

For $7 \leq n<10$, the reaction occurred over several microseconds, whereas for $n \geq 10$ prompt reaction $(<1 \mu \mathrm{s})$ was observed. Given that DME has a higher proton affinity than both methanol and water molecules, the explanation tentatively offered for observation of reaction (2), was that $\mathrm{H}_{3} \mathrm{O}^{+}$forms by proton migration onto $\mathrm{H}_{2} \mathrm{O}$ and the extra energy that this implies was more than compensated by the greater solvent stabilization by methanol for this ion when compared with protonated DME. ${ }^{13}$ Independent support for this suggestion comes from earlier work by Hiraoka et al., who also used mass spectrometry and obtained specific thermodynamic data which shows that the proton affinity of DME declines rapidly as water is added. ${ }^{14}$

Several authors have pointed out the close similarity between the ionic products obtained from ionization of pure methanol clusters and those observed from mixed methanolwater clusters. ${ }^{15-17}$ This similarity suggests that it is the stability of the products, rather than the specifics of the reaction dynamics, that determines the chemical outcome. A detailed review and discussion of previous findings for both methanol and other alcohol clusters has been provided by Garvey et al. ${ }^{17}$ More recently there have been several spectroscopic studies of small protonated methanol-water clusters which offer insight into both the structure and the charge location. ${ }^{18-20}$

Helium nanodroplets provide an alternative medium for exploring ion-molecule chemistry in molecular clusters. ${ }^{21}$ These droplets allow clusters to be grown in a cold environment (ca. $0.4 \mathrm{~K}$ ) and reaction can then be triggered by electron impact or photoionization. Potential advantages of exploring such ionmolecule reactions in helium nanodroplets include the very low initial temperature, the ease with which large clusters can be grown, and the possibility of using the surrounding helium to try and quench energetic reaction products which might otherwise undergo further decomposition in the gas phase. An early attempt to explore alcohol clusters in this way was carried out by Yang and co-workers, who used electron impact ionization to initiate the ion chemistry. ${ }^{22}$ As expected, protonated alcohol clusters were the dominant products, but other species identified included non-protonated alcohol cluster ions, $(\mathrm{ROH})_{n}{ }^{+}$, the dehydrogenated species, $(\mathrm{ROH})_{n} \mathrm{RO}^{+}$, and the $(\mathrm{ROH})_{n}\left(\mathrm{H}_{2} \mathrm{O}\right) \mathrm{H}^{+}$ species from reaction (2). However, the maximum observed cluster size was only $n=13$ and the apparatus was also known to be contaminated by significant quantities of water.

Here we report on a high resolution mass spectrometric study of methanol and ethanol clusters in helium nanodroplets. These clusters were produced in a dry environment and data for large clusters, with up to 100 alcohol molecules, were accessible because of the combination of large initial helium droplet sizes and a mass spectrometer with a wide operational mass range and a very high data collection rate. We report on a number of new findings, including production of cluster ions with up to five water molecules as a result of consecutive intra-cluster reactions.

\section{Experimental}

Helium droplets were produced by expanding ultra-pure ${ }^{4} \mathrm{He}$ (99.9999\%) at a stagnation pressure of 1-3 MPa through a $5 \mu \mathrm{m}$ diameter aperture into a vacuum. The nozzle is mounted on a copper cylinder which is cooled to $6-15 \mathrm{~K}$ by a closed-cycle cryostat (Sumitomo RDK-415 F50H). By variation of the stagnation pressure and nozzle temperature different expansion regimes can be accessed, resulting in mean helium droplet sizes of $N \sim 10^{4}$ (subcritical expansion) to $N>10^{6}$ (supercritical expansion). ${ }^{21}$ The cluster source conditions for mass spectra acquired in the present study were a helium stagnation pressure of $2 \mathrm{MPa}$ and a nozzle temperature of $9.5 \mathrm{~K}$, leading to a mean droplet size of $\sim 10^{5}$ helium atoms. Downstream of the nozzle the droplets pass through a conical skimmer with a $0.8 \mathrm{~mm}$ diameter aperture and then onwards through a differentially pumped pickup region where methanol (Sigma-Aldrich, 99.8\%) or ethanol (Sigma-Aldrich, 99.8\%) is introduced at a partial pressure near to $10^{-2} \mathrm{~Pa}$. In order to avoid air exposure and to keep the samples free of water, the alcohols were transferred from sealed bottles to the sample containers under inert conditions in a glove box.

The doped droplets undergo electron ionization at $70 \mathrm{eV}$ electron energy in a Nier type ion source. Cations are expected to be produced in a three-stage process, ${ }^{23-25}$ which first involves ionization to create $\mathrm{He}^{+}$, and the positive hole then hops from atoms to atom until it either encounters the dopant, in which case charge transfer occurs, or it localizes to produce a $\mathrm{He}_{n}{ }^{+}$cluster ion. In both cases excess energy is released and the ions can escape into the gas phase for detection by mass spectrometry. The resulting ions are accelerated to $40 \mathrm{eV}$ by an ion transfer guide into the extraction region of a commercial, orthogonal reflectron time-of-flight mass spectrometer (Tofwerk HTOF), providing a mass resolution, $m / \Delta m$, of $\sim 5000$ (FWHM). Detailed information on the experimental arrangement can be found elsewhere. ${ }^{26}$

\section{Results}

\section{A. Methanol clusters}

As in gas phase studies of methanol cluster ions, the dominant products in the current helium droplet study were protonated methanol cluster ions, $\mathrm{H}^{+}\left(\mathrm{CH}_{3} \mathrm{OH}\right)_{n}$. Our data extend to large clusters sizes, with clusters containing up to 100 methanol molecules being observed. In order to illustrate the types of ions produced, Fig. 1 shows sections of two mass spectra between $\mathrm{m} / \mathrm{z} 316$ and 348, one obtained using regular methanol and the other using fully deuterated methanol. In addition to the protonated methanol cluster ions, formed via reaction (1), 


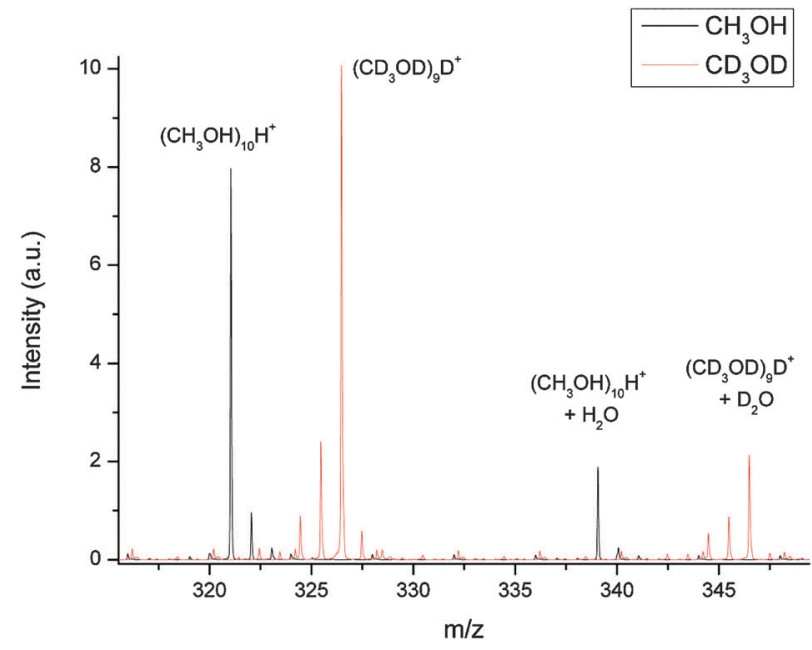

Fig. 1 Part of the mass spectrum obtained for methanol (black trace) and fully deuterated methanol (red trace). The most abundant products in this region are $\left(\mathrm{CH}_{3} \mathrm{OH}\right)_{10} \mathrm{H}^{+}$and its deuterated analogue but $\left(\mathrm{CH}_{3} \mathrm{OH}\right)_{10}\left(\mathrm{H}_{2} \mathrm{O}\right) \mathrm{H}^{+}$and $\left(\mathrm{CD}_{3} \mathrm{OD}\right)_{10}\left(\mathrm{D}_{2} \mathrm{O}\right) \mathrm{D}^{+}$are also significant products. Two weaker peaks immediately preceding the $\left(\mathrm{CD}_{3} \mathrm{OD}\right)_{n} \mathrm{D}^{+}$peaks are attributed to the substitution of one or two $\mathrm{H}$ atoms in place of $\mathrm{D}$ atoms, i.e. due to some small contamination from incompletely deuterated methanol in the commercially-supplied sample.

the other significant product derives from loss of $\mathrm{C}_{2} \mathrm{H}_{6} \mathrm{O}$ (or $\mathrm{C}_{2} \mathrm{D}_{6} \mathrm{O}$ ) from the methanol cluster ion, leaving behind a single water molecule. We presume that the ejected molecule is DME, $\mathrm{CH}_{3} \mathrm{OCH}_{3}$ (or $\mathrm{CD}_{3} \mathrm{OCD}_{3}$ ), as illustrated in reaction (2). The smallest cluster of this type detected in the current set of experiments was $\mathrm{H}^{+}\left(\mathrm{CH}_{3} \mathrm{OH}\right)_{4}\left(\mathrm{H}_{2} \mathrm{O}\right)$, but the signal was found to be exceptionally weak. The $\mathrm{H}^{+}\left(\mathrm{CH}_{3} \mathrm{OH}\right)_{n}\left(\mathrm{H}_{2} \mathrm{O}\right)$ ions become noticeably more prominent at $n=7$, although they are still nearly an order of magnitude weaker than the $\mathrm{H}^{+}\left(\mathrm{CH}_{3} \mathrm{OH}\right)_{7}$ ions. This increased prominence of $\mathrm{H}^{+}\left(\mathrm{CH}_{3} \mathrm{OH}\right)_{n}\left(\mathrm{H}_{2} \mathrm{O}\right)$ at $n=7$ is consistent with observations in previous gas phase studies, and in particular the identification of prompt production of this class of ions. ${ }^{10}$

The abundances of all of the $\mathrm{H}^{+}\left(\mathrm{CH}_{3} \mathrm{OH}\right)_{n}\left(\mathrm{H}_{2} \mathrm{O}\right)_{m}$ ions as a function of $n$ are summarized in Fig. 2. For clusters containing a single $\mathrm{H}_{2} \mathrm{O}$ molecule the distribution peaks at $n=9$ and then declines gradually as more methanol molecules are added. A new feature in this work is the recording of a second maximum, at $n=14$. Another new feature in the current work is the production of ions with up to 5 water molecules attached, implying that reaction (2) can occur on multiple occasions for sufficiently large methanol clusters. For production of additional water the rise to a maximum is slower and the maximum is more diffuse and skewed towards an increasing number of methanol molecules. Thus for two water molecules the signal begins to rise dramatically at $n=10$ and peaks at $n \approx 23$, while for three water molecules the initial rise occurs at $n=12$ and the peak abundance is around $n \approx 40$. For the production of four and five water molecules the increase in signal with the number of methanol molecules is very gradual and no obvious onset for production can be identified.

In an earlier report on the mass spectrometry of alcohol clusters in helium droplets, which included methanol and

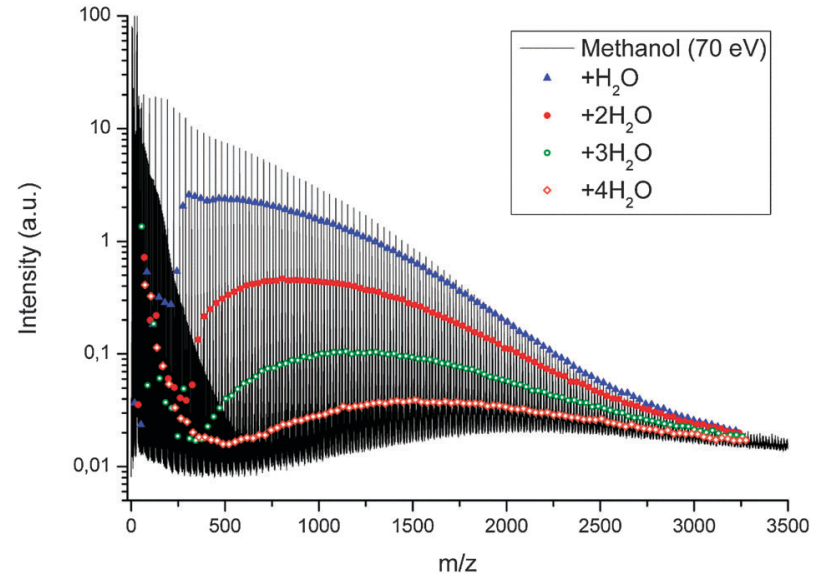

Fig. 2 Observed abundances of $\left(\mathrm{CH}_{3} \mathrm{OH}\right)_{10}\left(\mathrm{H}_{2} \mathrm{O}\right)_{m} \mathrm{H}^{+}$complexes for $m=1-4$.

heavier alcohols, substantial quantities of non-protonated cluster ions, $(\mathrm{ROH})_{n}{ }^{+}$, were detected in the gas phase. ${ }^{22}$ That earlier work employed a pulsed helium droplet source with an estimated mean droplet size of $6 \times 10^{4}$ helium atoms. The dehydrogenated species, $(\mathrm{ROH})_{n-1} \mathrm{RO}^{+}$, was also observed, with a typical abundance of roughly $50 \%$ of that of $(\mathrm{ROH})_{n}{ }^{+}$. By way of contrast $\left(\mathrm{CH}_{3} \mathrm{OH}\right)_{n}^{+}$ ions are negligible products in the current work and the dehydrogenated species are not seen. The precise reasons for these differences are unknown but there are differences in experimental conditions, including modest differences in droplet sizes. However, likely to be of more importance are the much drier conditions achieved in the present work, with only very small traces of background water being detected.

\section{B. Ethanol clusters}

There are considerable similarities between the methanol and ethanol data, but also some differences. The major products are protonated ethanol cluster ions, and similar to methanol the most significant other products are $\left(\mathrm{C}_{2} \mathrm{H}_{5} \mathrm{OH}\right)_{n}\left(\mathrm{H}_{2} \mathrm{O}\right)_{m} \mathrm{H}^{+}$cluster ions. We can clearly see the latter ions for up to $m=3$ : thereafter the signal becomes exceptionally weak. The data obtained are summarized in Fig. 3, where cluster signals extending up to $n \approx 100$ are seen.

For one water molecule in the ion product $(m=1)$ the data resemble those obtained for methanol in one important respect, i.e. a rapid rise from near zero signal for $n=7$ and a maximum abundance for $n=9$. However, the second maximum seen in the case of methanol is not seen for ethanol. The $m=2$ case in particular is somewhat skewed when compared to methanol. The really rapid rise in signal begins at $n=9$ and reaches a peak at $n=12$. Interestingly, there is a second maximum for the $m=2$ case at $n=18$; no second maximum was observed for the methanol case for $m=2$. The abundance of the $m=3$ ions is much lower than for $m=1$ and 2 cases and the first detectable $\left(\mathrm{C}_{2} \mathrm{H}_{5} \mathrm{OH}\right)_{n}\left(\mathrm{H}_{2} \mathrm{O}\right)_{3} \mathrm{H}^{+}$ions are found at $n=10$.

\section{Discussion}

In this work intra-cluster reactions leading to water production have been observed over a much wider range of methanol and 


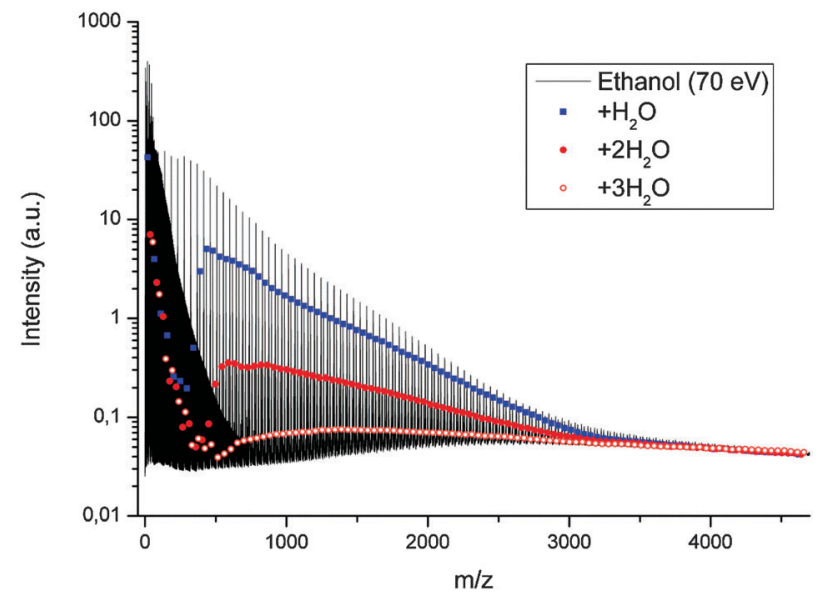

Fig. 3 Observed abundances of $\left(\mathrm{C}_{2} \mathrm{H}_{5} \mathrm{OH}\right)_{10}\left(\mathrm{H}_{2} \mathrm{O}\right)_{m} \mathrm{H}^{+}$complexes for $m=1-4$.

ethanol cluster sizes than reported previously. Of particular significance is the observation of consecutive intra-cluster reactions leading to the production of several water molecules within a cluster ion product. Protonated methanol cluster ions with more than one water molecule have been reported previously from reactions between water molecules and methanol clusters under electron impact, but not previously from reactions of pure methanol clusters. Likewise, the parallel observation for ethanol cluster ions is also new.

For small methanol clusters the signal for the water-containing product is a small fraction of that of the nearby protonated methanol signal. However, with increasing cluster size the relative abundance of the water-containing product grows until it eventually approaches that of the protonated methanol, as can be seen from Fig. 4. For $\mathrm{H}^{+}\left(\mathrm{CH}_{3} \mathrm{OH}\right)_{n}\left(\mathrm{H}_{2} \mathrm{O}\right)$ production, the abundance of this ion is already comparable to that of $\mathrm{H}^{+}\left(\mathrm{CH}_{3} \mathrm{OH}\right)_{n}$ at $n=10$, whereas $\mathrm{H}^{+}\left(\mathrm{CH}_{3} \mathrm{OH}\right)_{n}\left(\mathrm{H}_{2} \mathrm{O}\right)_{2}$ requires in the region of 30 methanol molecules for equivalence. For production of three or more water molecules in excess of

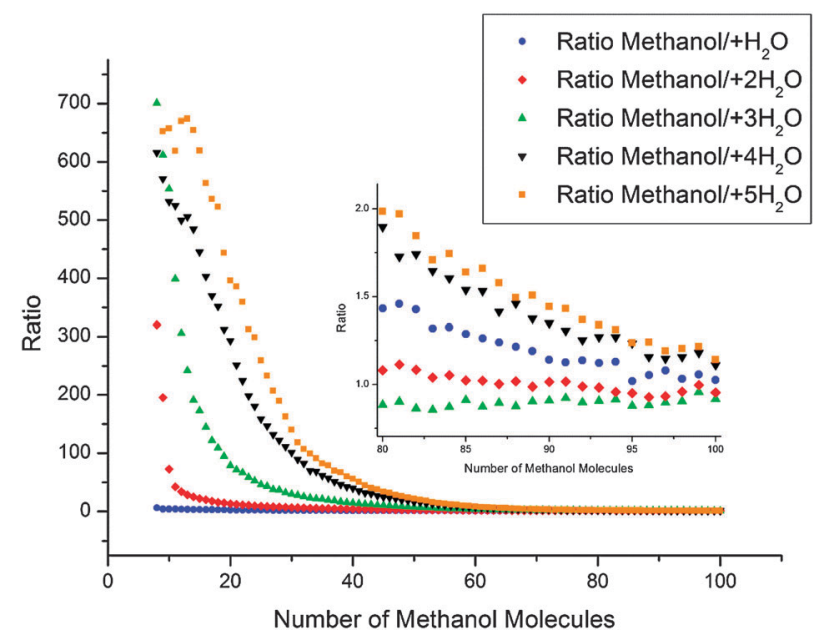

Fig. 4 Ratio of abundance of $\mathrm{H}^{+}\left(\mathrm{CH}_{3} \mathrm{OH}\right)_{n}$ signal relative to that of $\mathrm{H}^{+}\left(\mathrm{CH}_{3} \mathrm{OH}\right)_{n}$ $\left(\mathrm{H}_{2} \mathrm{O}\right)_{m}$ for $m=1-5$.
60 methanol molecules are required before the $\mathrm{H}^{+}\left(\mathrm{CH}_{3} \mathrm{OH}\right)_{n}\left(\mathrm{H}_{2} \mathrm{O}\right)_{m} /$ $\mathrm{H}^{+}\left(\mathrm{CH}_{3} \mathrm{OH}\right)_{n}$ ratio becomes close to unity.

The question now turns to the significance of these observations. As mentioned earlier, it has been suggested previously that the appearance of clusters containing water may be an indicator of $\mathrm{H}_{3} \mathrm{O}^{+}$formation within the methanol clusters, despite the higher proton affinities possessed by both methanol and dimethyl ether molecules. We presume that water is formed in these clusters by a process that begins with electrophilic attack of $\mathrm{H}^{+}$on the $\mathrm{OH}$ group in an adjacent $\mathrm{CH}_{3} \mathrm{OH}$ molecule, forming $\mathrm{H}_{2} \mathrm{O}$ and leaving behind a methyl cation. The $\mathrm{CH}_{3}{ }^{+}$can then combine with an adjacent methanol molecule to form protonated DME. Since DME has a higher proton affinity than methanol, one might predict the ejection of a protonated DME cation from the helium droplet, either on its own or solvated with methanol molecules, but this is not observed. Only traces of protonated DME were detected in our experiments and these are likely to be the result of the dehydration of the protonated methanol dimer, as observed in earlier work. ${ }^{12}$ Consequently, the proton must relocate from the DME to elsewhere in the cluster, leading to possible ejection of neutral DME. The fact that we never see water ejected from the cluster ions, regardless of the cluster size, suggests that the water plays a critical role in this charge transfer process and the most likely explanation is that the proton is transferred to the water molecule to create $\mathrm{H}_{3} \mathrm{O}^{+}$.

Our observations show that this process does not occur just once, but instead can repeat itself on one or more occasions with an efficiency that depends on the size of the methanol cluster. Thus we assume that the $\mathrm{H}_{3} \mathrm{O}^{+}$can make a proton available for a new electrophilic attack on a neighbouring methanol molecule, beginning another cycle of reaction which leads to further DME production. The proton is therefore acting effectively as a catalyst which drives reaction (2). The time from ion production to ion observation provides a relatively narrow window of $120 \mu \mathrm{s}$ within which to follow the reaction. Consequently, although we see a maximum of five water molecules produced within the methanol clusters, this may simply reflect the constraint of reaction kinetics rather than any thermodynamic limit. It is therefore possible the reaction goes further, but with some DME molecules retained within the ionic clusters. However, we think a runaway reaction that converts virtually all of the methanol to DME is unlikely because such a process would be energetically impeded by the unfavourable solvation of $\mathrm{H}_{3} \mathrm{O}^{+}$by DME when compared to methanol.

Garvey and co-workers have suggested structures for small $\mathrm{H}^{+}\left(\mathrm{CH}_{3} \mathrm{OH}\right)_{n}\left(\mathrm{H}_{2} \mathrm{O}\right)_{m}$ clusters which account for the most abundant ions observed in their mass spectrometric work on mixed methanol-water clusters. ${ }^{16,27}$ The underlying assumption is that the proton moves onto the $\mathrm{H}_{2} \mathrm{O}$ and becomes solvated by the methanol once a critical cluster size is reached. Evidence for this comes not only from mass spectrometry, but also from the infrared spectroscopy of small protonated mixed methanolwater clusters. ${ }^{19}$ Guided by earlier work on neutral and ionic clusters of both water and methanol, where structures derived from hydrogen-bonded five-membered rings could account for 
particularly stable species, a network of fused five-membered rings was proposed by Garvey et al. to account for the prominent species in their mass spectra. The smallest cluster that can deliver fully hydrogen-bonded $\mathrm{H}_{3} \mathrm{O}^{+}$in this manner is $\mathrm{H}^{+}\left(\mathrm{CH}_{3} \mathrm{OH}\right)_{7} \mathrm{H}_{2} \mathrm{O}$, via two fused five-membered rings with $\mathrm{H}_{3} \mathrm{O}^{+}$ occupying a central position. However, this structure has a dangling $\mathrm{O}-\mathrm{H}$ bond on one of the methanol molecules and to fully close all of the rings and therefore maximize the hydrogen bonding the cluster $\mathrm{H}^{+}\left(\mathrm{CH}_{3} \mathrm{OH}\right)_{9} \mathrm{H}_{2} \mathrm{O}$ is required. Once the possibility of the DME forming a hydrogen bond with any of the solvent molecules is removed, as it is for the closed ring structures, the DME becomes easier to eject from the ion.

The arguments above broadly account for the experimental observations reported by Garvey et al., since they are consistent with the onset for observing significant quantities of $\mathrm{H}^{+}\left(\mathrm{CH}_{3} \mathrm{OH}\right)_{n}\left(\mathrm{H}_{2} \mathrm{O}\right)$ at $n=7$ and the most abundant species at $n=9$. These suggestions also fit with the observations in the present work. The source of the small secondary abundance maximum for $\mathrm{H}^{+}\left(\mathrm{CH}_{3} \mathrm{OH}\right)_{n} \mathrm{H}_{2} \mathrm{O}$ at $n=14$ is unclear. Hydrogenbonded ring structures based on a central $\mathrm{H}_{3} \mathrm{O}^{+}$ion are possible for this stoichiometry, e.g. two seven-membered rings and a single six-membered ring, but this suggestion is speculative and the correct explanation for this rather modest maximum may lie elsewhere.

In the case of two water molecules the smallest cluster that maximizes the hydrogen bonding has four five-membered rings and corresponds to $\mathrm{H}^{+}\left(\mathrm{CH}_{3} \mathrm{OH}\right)_{10}\left(\mathrm{H}_{2} \mathrm{O}\right)_{2}$. Again, this is consistent with the sharp rise in cluster abundance observed in the present work, as well as that reported by Garvey and co-workers. ${ }^{17}$ However, no data of this type have been reported previously for $\mathrm{H}^{+}\left(\mathrm{CH}_{3} \mathrm{OH}\right)_{n}\left(\mathrm{H}_{2} \mathrm{O}\right)_{3}$. If we follow the same reasoning as Garvey et al., then the first cluster which can satisfy the requirement for a fully hydrogen bonded structure requires five fivemembered rings, corresponding to $\mathrm{H}^{+}\left(\mathrm{CH}_{3} \mathrm{OH}\right)_{12}\left(\mathrm{H}_{2} \mathrm{O}\right)_{3}$. Again, this fits well with experiments in the present work, where the $\mathrm{H}^{+}\left(\mathrm{CH}_{3} \mathrm{OH}\right)_{n}\left(\mathrm{H}_{2} \mathrm{O}\right)_{3}$ signal rises sharply at $n=12$. Unfortunately, we cannot extend this argument to products with four and five water molecules because in those cases the signal levels are weak for small methanol clusters and provide no evidence of a rapid acceleration of cluster ion production at a given cluster size. In any case the idea of identifying stable structures must break down for sufficiently large clusters because of the increasing complexity of the potential energy landscape and the near degeneracy of multiple potential energy minima. Furthermore, although we have no specific evidence for this from the current data, at sufficiently large sizes the clusters may fold to form quasi-spherical structures. Nevertheless, our observations for $\mathrm{H}^{+}\left(\mathrm{CH}_{3} \mathrm{OH}\right)_{n}\left(\mathrm{H}_{2} \mathrm{O}\right)_{m}$, where $m=1-3$, support the idea that protonated methanol cluster can undergo reaction and subsequent proton transfer to generate $\mathrm{H}_{3} \mathrm{O}^{+}\left(\mathrm{H}_{2} \mathrm{O}\right)_{m}$ ions at the core of the clusters. These clusters are then solvated by methanol through a hydrogen bonding network that seems to show additional structural stability when composed of several complete five-membered rings.

The abundance pattern for $\left(\mathrm{C}_{2} \mathrm{H}_{5} \mathrm{OH}\right)_{n}\left(\mathrm{H}_{2} \mathrm{O}\right) \mathrm{H}^{+}$matches that of $\mathrm{H}^{+}\left(\mathrm{CH}_{3} \mathrm{OH}\right)_{n}\left(\mathrm{H}_{2} \mathrm{O}\right)$ rather closely, so we assume a parallel interpretation applies. When two water molecules are present the abundance is at maximum at a much smaller value of $n$ for ethanol than for methanol. A contribution to this difference may come from the stronger hydrogen bonding in ethanol than in methanol, the difference being roughly $170 \mathrm{~cm}^{-1}$ per molecule based on dimer binding energies for the neutral molecules. ${ }^{28}$ Thus each ethanol molecule added will result in an additional 35 helium atoms being evaporated beyond that for methanol, assuming that each helium atoms removes $5 \mathrm{~cm}^{-1} .^{20}$ This will result in smaller droplets for ethanol than for methanol, with a differential effect on the pickup probability as more and more alcohol molecules are added. However, given the large initial size of the helium droplets, this effect alone cannot account for the difference in abundance maxima. Presumably other factors are at work here, most likely very different post-ionization fragmentation dynamics for the two different alcohols.

\section{Conclusions}

The electron impact ionization of helium droplets doped with large methanol and ethanol clusters has been investigated for the first time. Using high resolution mass spectrometry, well-resolved spectra for clusters containing up to 100 molecules have been detected. Much of the ion chemistry matches that seen in previous gas phase work, with the dominant product in the gas phase being the protonated species $\mathrm{H}^{+}(\mathrm{ROH})_{n}$. Also seen are the $\mathrm{H}^{+}(\mathrm{ROH})_{n}\left(\mathrm{H}_{2} \mathrm{O}\right)_{m}$ ions. In previous gas phase work on pure methanol clusters only ions with $m=1$ and 2 were detected and these were formed by the deliberate addition of water. In the present study the clusters were sufficiently large to see up to $m=$ 5 and dry conditions were used with negligible levels of water contamination, establishing that these ions are formed by intracluster reactions after ionization of the helium droplet. For the analogous ions for ethanol, clusters with up to $m=3$ were observed.

The distribution of signal as a function of $n$ for a given $m$, at least for $m \leq 3$, is consistent with the most stable structures deriving from a series of complete 5-membered hydrogen bonding rings built upon a central $\mathrm{H}_{3} \mathrm{O}^{+}$solute ion. For $m=4$ and 5 the ion abundances vary smoothly with cluster size. The large number of methanol molecules required to form closed ring structures with no dangling bonds for these values of $m$ are expected to create a much flatter and more complex potential energy landscape, which will no longer deliver measurable excess stabilities once the clusters become sufficiently large.

\section{Acknowledgements}

The work was supported by the FWF, Wien (P19073) and the European Commission, Brussels. AME is grateful to the EU, under COST action CM0805, for travel funds and PB gratefully acknowledge a dissertation grant from the Vice-Rectorate for research of the University of Innsbruck. MMG. acknowledges the National Council for the Improvement of Higher Education (CAPES), process no. 4752/11-2, the Foundation for Research 
Support of Minas Gerais State (FAPEMIG) and the National Council for Scientific and Technological Development (CNPq).

\section{References}

1 C. J. D. von Grotthus, Ann. Chim., 1806, LVIII, 54.

2 M. Eigen and L. de Maeyer, Proc. R. Soc. London, 1958, A247, 505.

3 G. Zundel and H. Metzger, Z. Phys. Chem., 1968, 244, 456.

4 E. Kochanski, R. Kelterbaum, S. Klein, M. M. Rohmer and A. Rahmouni, Adv. Quantum Chem., 1997, 28, 273.

5 G. Niedner-Schatteburg and V. Bondybey, Chem. Rev., 2000, 100, 4059.

6 R. Ludwig, ChemPhysChem, 2004, 5, 1495.

7 H.-C. Chang, C.-C. Wu and J.-L. Kuo, Int. Rev. Phys. Chem., 2005, 24, 553.

8 H.-C. Chang, J. C. Jiang, S. H. Lin, Y. T. Lee and H.-C. Chang, J. Phys. Chem. A, 1999, 103, 2941.

9 K. R. Ryan, L. W. Sieck and J. H. Futrell, J. Chem. Phys., 1964, 41, 111.

10 M. B. S. Munson, J. Am. Chem. Soc., 1965, 87, 5313.

11 L. W. Sieck, J. H. Futrell and F. P. Abramson, J. Chem. Phys., 1966, 45, 2859.

12 S. Morgan and A. W. Castleman, Jr, J. Am. Chem. Soc., 1987, 109, 2867.

13 S. Morgan, R. G. Keesee and A. W. Castleman, Jr, J. Am. Chem. Soc., 1989, 111, 3841.

14 K. Hiraoka, E. P. Grimsrud and P. Kebarle, J. Am. Chem. Soc., 1974, 96, 3359.
15 M. S. El-Shall, C. Marks, L. W. Sieck and M. Meot-Ner, J. Phys. Chem., 1992, 96, 2045.

16 O. Kosto, L. Belau, K. R. Wilson and M. Ahmed, J. Phys. Chem. A, 2008, 112, 9555.

17 J. F. Garvey, W. J. Herron and G. Vaidyanathan, Chem. Rev., 1994, 94, 1999.

18 C.-C. Wu, J. C. Jiang, D. W. Boo, S. H. Lin, Y. T. Lee and H.-C. Chang, J. Chem. Phys., 2000, 112, 176.

19 C.-C. Wu, C. Chaudhuri, J. C. Jiang, Y. T. Lee and H.-C. Chang, J. Phys. Chem. A, 2004, 108, 2859.

20 K. I. Suhara, A. Fujii, K. Mizuse, N. Mikami and J.-L. Kuo, J. Chem. Phys., 2007, 126, 194306.

21 J. P. Toennies and A. F. Vilesov, Angew. Chem., Int. Ed., 2004, 43, 2622.

22 S. Yang, S. M. Brereton and A. M. Ellis, Int. J. Mass Spectrom., 2006, 253, 79.

23 B. E. Callicoatt, K. Förde, T. Ruchti, L. Jung and K. C. Janda, J. Chem. Phys., 1998, 108, 9371.

24 W. K. Lewis, M. Lindsay, R. J. Bemish and R. E. Miller, J. Am. Chem. Soc., 2005, 127, 7235.

25 A. M. Ellis and S. F. Yang, Phys. Rev. A: At., Mol., Opt. Phys., 2007, 76, 032714.

26 L. An der Lan, P. Bartl, C. Leidlmair, H. Schöbel, R. Jochum, S. Denifl, T. D. Märk, A. M. Ellis and P. Scheier, J. Chem. Phys., 2011, 135, 044309.

27 W. J. Herron, M. Todd Coolbaugh, G. Vaidyanathan, W. R. Peifer and J. F. Garvey, J. Am. Chem. Soc., 1992, 114, 3684 .

28 E. E. Fileti, P. Chaudhuri and S. Canuto, Chem. Phys. Lett., 2004, 400, 494. 